\title{
Femoroacetabular impingement: normal values of the quantitative morphometric parameters in asymptomatic hips
}

\author{
Marianne Lepage-Saucier • Cécile Thiéry • \\ Ahmed Larbi • Frédéric E. Lecouvet • \\ Bruno C. Vande Berg • Patrick Omoumi
}

Received: 20 January 2014 / Revised: 13 March 2014 / Accepted: 31 March 2014 /Published online: 27 April 2014

(C) European Society of Radiology 2014

\begin{abstract}
Objective To determine the means and the reference intervals of the quantitative morphometric parameters of femoroacetabular impingement (FAI) in normal hips with high-resolution computed tomography (CT).

Methods We prospectively included 94 adult individuals who underwent CT for thoracic, abdominal or urologic pathologies. Patients with a clinical history of hip pathology and/or with osteoarthritis on CT were excluded. We calculated means and $95 \%$ reference intervals for imaging signs of cam-type (alpha angle at $90^{\circ}$ and $45^{\circ}$ and femoral head-neck offset) and pincer-type impingement (acetabular version angle, lateral centre-edge angle and acetabular index).

Results The $95 \%$ reference interval limits were all far beyond the abnormal thresholds found in the literature for cam-type and to a lesser extent for pincer-type FAI. The upper limits of the reference intervals for the alpha angles $\left(\right.$ at $90^{\circ} / 45^{\circ}$ ) were $68^{\circ} / 83^{\circ}$ (men) and $69^{\circ} / 84^{\circ}$ (women), compared to thresholds from the literature $\left(50^{\circ}\right.$, $55^{\circ}$ or $\left.60^{\circ}\right)$. Reference intervals were similar between genders for cam-type parameters, and slightly differed for pincer-type. Conclusion The $95 \%$ reference intervals of morphometric measurements of FAI in asymptomatic hips were beyond the
\end{abstract}

M. Lepage-Saucier $\cdot$ C. Thiéry $\cdot$ A. Larbi $\cdot$ F. E. Lecouvet $\cdot$

B. C. Vande Berg $\cdot$ P. Omoumi $(\triangle)$

Cliniques Universitaires Saint Luc - Université Catholique de

Louvain, Woluwe-Saint-Lambert, Belgium

e-mail: patrick.omoumi@chuv.ch

M. Lepage-Saucier

e-mail: marianne.lepage-saucier@umontreal.ca

P. Omoumi

Department of Diagnostic and Interventional Radiology, Lausanne

University Hospital, Rue du Bugnon 46, 1011 Lausanne, Switzerland

\section{Lepage-Saucier}

Hôpital Notre-Dame - Centre hospitalier de l'Université de Montréal, 1560, rue Sherbrooke Est Montréal, H2L 4M1 Québec, Canada abnormal thresholds, which was especially true for cam-type FAI. Our results suggest the need for redefining the current morphometric parameters used in the diagnosis of FAI.

Key Points

- $95 \%$ reference intervals limits of FAI morphotype were beyond currently defined thresholds.

- Reference intervals of pincer-type morphotype measurements were close to current definitions.

- Reference intervals of cam-type morphotype measurements were far beyond the current definitions.

- Current morphometric definitions of cam-type morphotype should be used with care.

Keywords Hip · Femoroacetabular impingement . Multidetector computed tomography $\cdot$ Reference value . Normal value $\cdot$ Osteoarthritis · Anatomy $\cdot$ Variant
Abbreviations
CT computed tomography
FAI femoroacetabular impingement
ICC intraclass correlation coefficients
MPR multiplanar reformatting
MRI magnetic resonance imaging
OA osteoarthritis
PACS picture archiving and storage system

\section{Introduction}

There has been increasing evidence that femoroacetabular impingement (FAI) causes chondrolabral abnormalities in the young adult population, especially young athletes, leading to pain and premature osteoarthritis (OA) [1-4]. FAI is defined as an impingement between the head-neck junction of 
the femur and the acetabular rim due to altered morphology of either or both of these structures. It can be classified as (1) cam-type impingement if the anterolateral or lateral femoral head-neck junction or the entire femoral head is prominent, (2) pincer-type impingement if the acetabulum presents general or focal overcoverage or (3) a combination of cam-type and pincertype impingement [5]. It has been suggested that early diagnosis and treatment of FAI may prevent irreversible degenerative changes, with surgery being the preferred treatment [6-9].

The diagnosis of FAI is mainly based on the clinical examination, but many morphometric parameters at imaging have also been proposed and used as part of the diagnostic workup of FAI $[1,5]$. These parameters have been validated on radiographs, magnetic resonance imaging (MRI) and on computed tomography (CT) [10-14]. However, to date, there is no consensus among authors as to the threshold values to define abnormal patients using these parameters, and only few studies have defined the normal range of the FAI morphometric values in normal hips [5, 13, 15-21]. Furthermore, several authors have recently pointed out the high prevalence of FAI signs in the asymptomatic population based on the currently used cut-off values and the need to redefine these abnormal thresholds [18, 19, 22-26]. As suggested by other authors, more work is needed to firmly establish the normal range of these morphometric parameters [17].

CT represents the imaging technique with the highest contrast and spatial resolution available for the 3D assessment of bone morphometry. To the best of our knowledge, the range of values of FAI morphometric parameters has never been established in a general population using CT.

The goal of this study was to determine the means and the $95 \%$ reference intervals of the quantitative morphometric parameters of FAI in asymptomatic hips using highresolution multidetector $\mathrm{CT}$, in order to statistically define abnormal thresholds for these parameters.

\section{Materials and methods}

\section{Patient population}

Institutional ethical committee approval was obtained at our institution with written informed consent from all participating patients. No additional radiation than what was already needed for their current medical condition was given to any of the patients included in our study. We prospectively included all consecutive adult patients who obtained a (thoraco-)abdominopelvic CT for thoracic, abdominal or urogenital indications, from December 2011 to March 2012, in our institution. A questionnaire with "yes" or "no" answers was given to all participating patients about their clinical history: current or past hip/groin pain, any medical or surgical hip joint history, any history of hip trauma or any history of hip problems during childhood. All the patients who gave a positive answer to at least one of these questions were excluded.
We then excluded all patients with $\mathrm{CT}$ signs of OA on at least one hip. OA was defined at $\mathrm{CT}$ on the basis of strict criteria including the presence of at least one of the following: joint space narrowing, osteophytes, or subchondral bone changes including sclerosis or cysts. Finally, hips with any of the following diagnosis on CT were excluded: hip cartilage calcium deposition disease, post-traumatic deformity, Legg-Calve-Perthes disease, osteonecrosis, slipped capital femoral epiphysis, hip dysplasia or focal bone lesion.

\section{CT examination}

CT images were obtained on a 40-, 64- or 256-detector row scanner (Philips Brilliance 40, Brilliance 64 and ICT 256 respectively; Philips Medical Systems, Best, the Netherlands) with patients head first in supine position. The following parameters were used: tube voltage, $120 \mathrm{kVp}$; reference tube current-time product, 90-200 mAs with automated dose modulation. The CT covered the entire pelvis, including the ischial tuberosities. The raw data were reconstructed by using a bone algorithm.

Image analysis

Two fellowship-trained musculoskeletal radiologists (observer 1, 1.5 years of experience; observer 2, 4 years of experience) independently reviewed the $\mathrm{CT}$ images using our picture archiving and storage system (PACS) (Carestream PACS 11.3, Carestream Health Company, Raanana, Israel). The observers, both with previous practice of hip morphometry, together reviewed published morphometric parameters of FAI and trained on 10 hips that were not part of the study (Figs. 1, 2, 3 and 4). Prior to the study, all examinations were randomized (alphabetically ordered). Observer 1 executed the measurements on all hips according to the following procedure. Reformatted images in axial, axial oblique and double oblique planes were generated from the volumetric raw data. Then, a 100-mm-thick coronal multiplanar reformatted (MPR) image with an averaging of pixel intensities was also obtained, simulating a pelvic radiograph (Fig. 4) with the tip of the coccyx located approximately $2 \mathrm{~cm}$ above the pubic symphysis superior cortex on the midline [5]. In total, four reformatted images were created, cross-referencing with the sagittal and coronal planes:

- Axial oblique plane (equivalent to radial plane) through the centre of the femoral head and the anterior aspect of the femoral head-neck junction, along the axis of the femoral neck (alpha angle $90^{\circ}$ and femoral head-neck offset) (Fig. 1).

- Double oblique plane (equivalent to radial plane) through the centre of the femoral head and the anterosuperior aspect of the femoral head-neck junction at $45^{\circ}$ to the axial plane, along the axis of the femoral neck (alpha angle $45^{\circ}$ ) (Fig. 2).

- Axial plane through the deepest part of the acetabula, parallel to the line through the posterior aspect of the acetabula (acetabular version angle) (Fig. 3). 

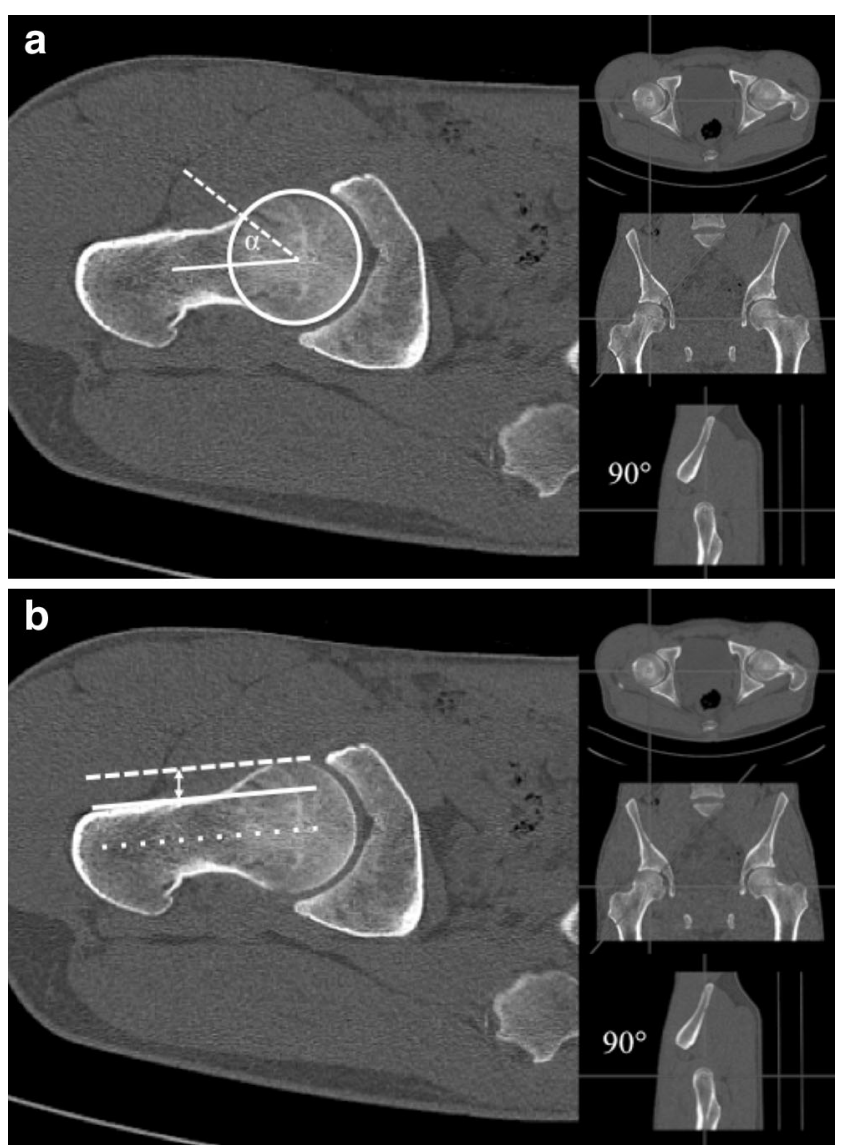

Fig. 1 a For the alpha angle $90^{\circ}$ measurement, a circle was used to delineate the femoral head circumference. A first line was drawn between the centre of the circle and the centre of the narrowest part of the femoral neck (solid line). A second line was then traced from the centre of the circle to the point where the femoral neck extends beyond the femoral head circle (dashed line). The alpha angle was measured between those two lines. b The femoral head-neck offset is a measurement of the distance between two lines at the anterior aspect of the femoral neck (solid line) and at the anterior surface of the femoral head (dashed line). Those lines are parallel to the femoral neck (dotted line)

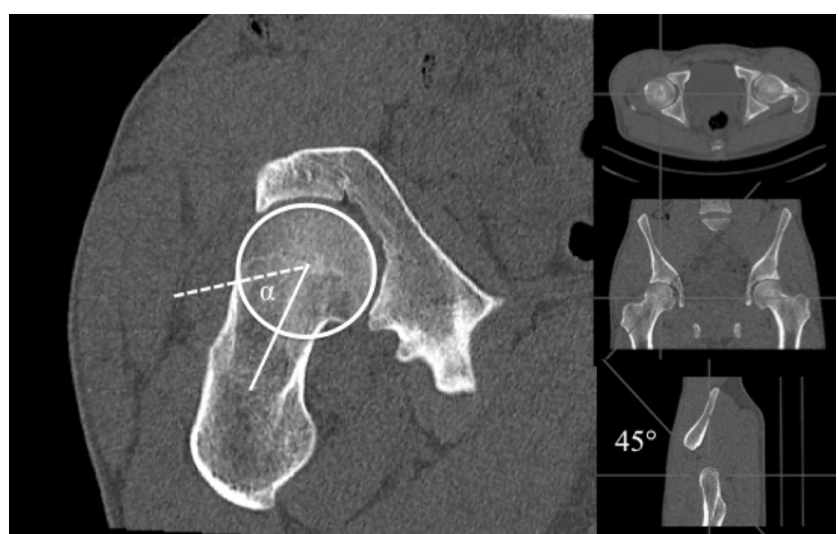

Fig. 2 The measurement of the alpha angle $45^{\circ}$ was performed according to the same definition as for the alpha angle $90^{\circ}$, on a double oblique reformatted image, which is equivalent to a radial reformatting at the anterosuperior position of the head-neck junction

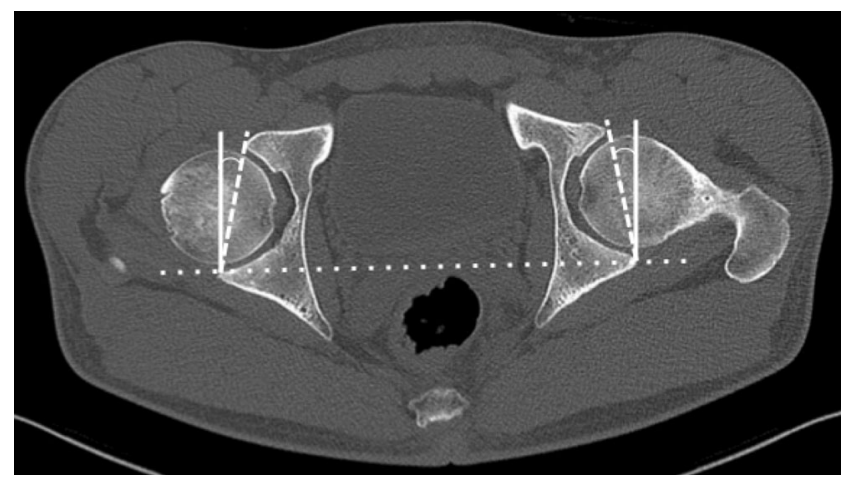

Fig. 3 For the measurement of the acetabular version angle, a first line was traced between the posterior acetabular walls at the level where the acetabulum is the deepest (dotted line). The acetabular version angle was measured between a line perpendicular to that first line (solid line) and another one that joins the anterior and posterior walls of the acetabulum (dashed line)

- 100-mm-thick coronal MPR parallel to a line joining the lowest aspect of the radiographic teardrops (lateral centreedge angle and acetabular index) (Fig. 4).

To ensure the consistency of the measurements made by observer 1 , observer 2 performed the measurements on a subset of patients selected randomly (40 hips) according to the same procedure, and the interobserver agreement was calculated.

\section{Statistical analysis}

For all the morphometric parameters, the mean values and standard deviations were determined. The one-sample Kolmogorov-Smirnov test was used to test whether data

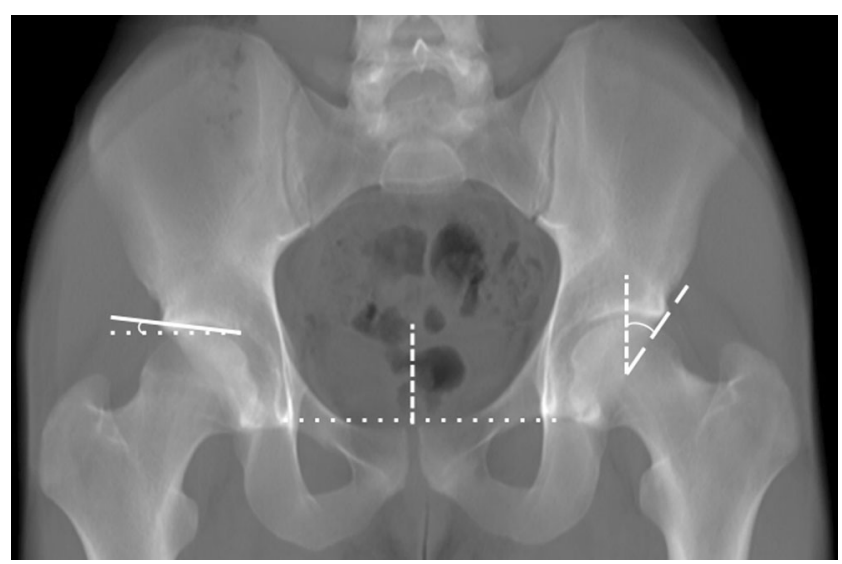

Fig. 4 Method of measurement of the acetabular index (right hip) and lateral centre-edge angle (left hip). The acetabular index (right hip) was measured between a line joining the inferior aspect of the teardrops (dotted line) and a line between the medial and lateral edge of the acetabulum roof (solid line). The lateral centre-edge angle (left hip) was measured between a line perpendicular to the inferior teardrop line (dashed line) and another line traced between the femoral head centre and lateral acetabular roof margin (long dashed line) 
samples were normally distributed. Double-sided $95 \%$ reference intervals were calculated following Clinical and Laboratory Standards Institute (CLSI) guidelines C28-A3 [27]. The normal distribution method was used for normally distributed variables. When the test for normal distribution failed, the non-parametric percentile method was used for sample sizes larger than 120, and the robust method (bootstrap method using 5,000 replications) for sample sizes below 120 . The $90 \%$ confidence intervals were given for the reference limits.

The proportion of men and women among the included and excluded patients was compared using a Chi-squared test.

Interobserver agreement was obtained with intraclass correlation coefficients (ICC). We used an absolute agreement model (systematic differences between readers considered relevant) for single measures (estimating the reliability of single ratings). The coefficients were analysed as follows: $\leq 0=$ poor, $0.01-0.20=$ slight, $0.21-0.40=$ fair, $0.41-0.60=$ moderate, $0.61-0.80=$ substantial and $\geq 0.81=$ almost perfect agreement. A $p$ value of 0.05 was considered statistically significant for all analyses. Statistical analyses were performed using dedicated software (MedCalc version 11.6; MedCalc Software, Mariakerke, Belgium).

\section{Results}

Patient population

Of all the patients who underwent $\mathrm{CT}$ examination for thoracic, abdominal or urogenital indications in our institution during the 3-month period, 367 patients agreed to be part of the study. A total of 119 patients were excluded on the basis of at least one positive answer to the questionnaire and 154 on the basis of the presence of OA or other hip pathologies at CT. For the excluded patients, the mean age was 63.2 (SD 11.8) years old (Table 1). In total, 188 hips of 94 patients were included in

Table 1 Included and excluded patients

\begin{tabular}{lrlr}
\hline & Number & Mean age & SD \\
\hline Total included patients & 94 & 49.0 & 16.6 \\
$\quad$ Men & 49 & 47.1 & 16.9 \\
Women & 45 & 51.2 & 16.2 \\
Total excluded patients & 273 & 63.2 & 11.8 \\
$\quad$ Men & 164 & 64.8 & 10.8 \\
Women & 109 & 60.6 & 12.7 \\
Positive answer in questionnaire & 119 & 62.4 & 11.7 \\
Men & 57 & 65.6 & 9.9 \\
$\quad$ Women & 62 & 59.2 & 12.4 \\
Positive CT findings & 154 & 63.8 & 11.8 \\
$\quad$ Men & 107 & 64.4 & 11.3 \\
Women & 47 & 62.4 & 13.0 \\
\hline
\end{tabular}

the study (49 men and 45 women). The mean age of the included patients was 49.0 (SD 16.6)years old (Table 1). There was no statistically significant difference in the proportion of male and female individuals among the excluded and included patients $(p=0.07)$.

Image analysis

For the cam-type morphotype, the means were $51(\mathrm{SD} 9)^{\circ}$ for the alpha angles at $90^{\circ}, 59(\mathrm{SD} 13)^{\circ}$ for the alpha angles at $45^{\circ}$ and 9 (SD 2) $\mathrm{mm}$ for the femoral head-neck offset, when considering all patients together. For the pincer-type morphotype, the means were 19 (SD 6) ${ }^{\circ}$ for the acetabular version angle, $32(\mathrm{SD} 6)^{\circ}$ for the lateral centre-edge angle and $6(\mathrm{SD} \mathrm{5})^{\circ}$ for the acetabular index, when considering all patients together. Gender-specific and side-specific means and reference intervals are reported in Tables 2 and 3.

\section{Interobserver agreement}

We found substantial to almost perfect agreement for all quantitative morphometric parameters measured in our study as seen in Table 4.

\section{Discussion}

Imaging criteria are part of the diagnostic workup of FAI, along with the clinical examination $[1,5]$. When morphological abnormalities are detected on the basis of these criteria, surgery has been advocated by some authors in order to alleviate the symptoms and possibly avoid the progression to early OA $[7-9,28]$. Prior studies have used different cut-off values for the morphometric parameters of FAI [5, 13, 15-20]. Furthermore, recent studies have pointed out the high prevalence of FAI signs in the asymptomatic population based on the currently used thresholds, emphasizing the need for adjustment of these cut-offs [18, 22-24, 29].

Reference intervals can be used to define the variation range of a parameter in the normal population, which may be helpful in the differentiation of normal from abnormal [30]. By definition, reference intervals contain $95 \%$ of values of a normally distributed variable in the normal population, if calculated from a representative sample. The lower and upper limits of the $95 \%$ reference intervals can thus be used as the threshold between normal and abnormal subjects. In this study, means and $95 \%$ reference intervals of the quantitative morphometric parameters of FAI were determined in asymptomatic patients using high-resolution multidetector $\mathrm{CT}$.

For cam-type FAI, abnormal thresholds derived from the $95 \%$ reference intervals were beyond the abnormal thresholds found in the literature. For example, the upper limits of the reference intervals calculated for the alpha angles at $90^{\circ}$ and 
Table 2 Means, $95 \%$ reference intervals and current abnormal cut-offs from the literature for the quantitative morphometric parameters of cam-type FAI

\begin{tabular}{|c|c|c|c|c|c|c|}
\hline & Patients & Means & SD & $\begin{array}{l}\text { Lower limits of } 95 \% \\
\text { reference interval* }\end{array}$ & $\begin{array}{l}\text { Upper limits of } 95 \% \\
\text { reference interval }\end{array}$ & Abnormal cut-offs from the literature \\
\hline \multirow[t]{4}{*}{ Alpha angle at $90^{\circ}\left(^{\circ}\right)$} & Men & 50 & 9 & $33[31 ; 36]$ & $68[65 ; 70]$ & \multirow[t]{4}{*}{$>50^{\circ}[22] ;>55^{\circ}[13] ;>60^{\circ}[19]$} \\
\hline & Women & 50 & 9 & $32[30 ; 35]$ & $69[66 ; 72]$ & \\
\hline & Right & 50 & 9 & $33[30 ; 35]$ & $67[65 ; 70]$ & \\
\hline & Left & 51 & 9 & $30[27 ; 33]$ & $68[65 ; 72]$ & \\
\hline \multirow[t]{4}{*}{ Alpha angle at $45^{\circ}\left(^{\circ}\right)$} & Men & 59 & 12 & $36[32 ; 39]$ & $83[79 ; 86]$ & \multirow[t]{4}{*}{$>50^{\circ}[22] ;>55^{\circ}[13] ;>60^{\circ}[19]$} \\
\hline & Women & 58 & 13 & $32[28 ; 36]$ & $84[80 ; 88]$ & \\
\hline & Right & 59 & 12 & $35[32 ; 39]$ & $82[79 ; 86]$ & \\
\hline & Left & 59 & 13 & $33[29 ; 37]$ & $85[81 ; 88]$ & \\
\hline \multirow[t]{4}{*}{ Femoral head-neck offset (mm) } & Men & 9 & 2 & $6[6 ; 7]$ & $12[12 ; 13]$ & \multirow[t]{4}{*}{$<8 \mathrm{~mm}[18]$} \\
\hline & Women & 8 & 2 & $5[4 ; 5]$ & $11[11 ; 12]$ & \\
\hline & Right & 9 & 2 & $5[5 ; 6]$ & $12[12 ; 13]$ & \\
\hline & Left & 9 & 2 & $5[5 ; 6]$ & $12[11 ; 12]$ & \\
\hline
\end{tabular}

*Data are limits of $95 \%$ reference intervals, followed by $90 \%$ confidence intervals in brackets

$45^{\circ}$ were $68^{\circ}$ and $83^{\circ}$ (men) and $69^{\circ}$ and $84^{\circ}$ (women), respectively, which are much higher than the $50^{\circ}, 55^{\circ}$ or $60^{\circ}$ thresholds previously proposed $[13,17,19]$ (Table 2). Of note, according to our data, the alpha angle was greater at the anterosuperior position (alpha angle $45^{\circ}$ ) than at the anterior position (alpha angle $90^{\circ}$ ) for both men and women, which is in agreement with other data in the literature [17, 19, 31]. Some of the variation between our results and previously reported values might be explained by the difference in the imaging modalities [17]. We used CT, which has high contrast and spatial resolution and allows easy delineation of the periphery of the femoral head and neck, and which could lead to potentially more accurate measurements than other techniques such as MR imaging.

Recently, several authors noted the high prevalence of FAI signs in the asymptomatic population on radiography and cross-sectional imaging based on the previously described cut-off values [18, 23, 24, 29]. In a retrospective study on young asymptomatic subjects, Chakraverty et al. recently showed that at least one abnormal cam or pincer morphometric parameter was visualized in $66 \%$ of joints, and two or more abnormal parameters were present in $29 \%$ of joints [22]. The means that we calculated for the cam and pincer signs were very close to those obtained in that study. In a study by Sutter et al., the alpha angle did not allow adequate differentiation of healthy individuals from symptomatic patients, so the authors suggested an increase of the alpha angle threshold from $50-55^{\circ}$ to $60^{\circ}$, in order to improve specificity [19]. They further concluded that the alpha angle is not an accurate method for distinguishing asymptomatic volunteers from patients with clinical FAI, because of the large overlap of alpha angles between these two populations [19]. The reported high

Table 3 Means, $95 \%$ reference intervals and current abnormal cut-offs from the literature for the quantitative morphometric parameters of pincer-type FAI

\begin{tabular}{|c|c|c|c|c|c|c|}
\hline & Patients & Means & $\mathrm{SD}$ & $\begin{array}{l}\text { Lower limits of } 95 \% \\
\text { reference interval* }\end{array}$ & $\begin{array}{l}\text { Upper limits of } 95 \% \\
\text { reference interval }\end{array}$ & Abnormal cut-offs from the literature \\
\hline \multirow[t]{4}{*}{ Acetabular version angle $\left(^{\circ}\right)$} & Men & 17 & 5 & $7[5 ; 8]$ & $27[26 ; 29]$ & \multirow[t]{4}{*}{$<15^{\circ}[20]$} \\
\hline & Women & 21 & 6 & $10[8 ; 12]$ & $32[30 ; 33]$ & \\
\hline & Right & 19 & 5 & $8[6 ; 10]$ & $29[28 ; 31]$ & \\
\hline & Left & 19 & 6 & $7[6 ; 9]$ & $30[29 ; 32]$ & \\
\hline \multirow[t]{4}{*}{ Lateral centre-edge angle $\left(^{\circ}\right)$} & Men & 35 & 6 & $22[20 ; 24]$ & $47[45 ; 49]$ & \multirow[t]{4}{*}{$\geq 45^{\circ}[16] ; \geq 40^{\circ}[5]$} \\
\hline & Women & 32 & 6 & $21[20 ; 22]$ & $44[42 ; 46]$ & \\
\hline & Right & 33 & 6 & $21[19 ; 23]$ & $46[44 ; 48]$ & \\
\hline & Left & 33 & 6 & $21[19 ; 23]$ & $46[44 ; 48]$ & \\
\hline \multirow[t]{4}{*}{ Acetabular index $\left({ }^{\circ}\right)$} & Men & 6 & 5 & $-3[-4 ;-2]$ & $14[13 ; 16]$ & \multirow[t]{4}{*}{$<0^{\circ}[15]$} \\
\hline & Women & 6 & 4 & $-1[-3 ; 0]$ & $16[15 ; 17]$ & \\
\hline & Right & 7 & 4 & $-3[-4 ;-2]$ & $15[13 ; 17]$ & \\
\hline & Left & 7 & 5 & $-2[-4 ;-1]$ & $15[14 ; 16]$ & \\
\hline
\end{tabular}

*Data are limits of $95 \%$ reference intervals, followed by $90 \%$ confidence intervals in brackets 
Table 4 Interobserver agreement

Interobserver agreement

$\begin{array}{ll}\text { Cam impingement } & \\
\text { Alpha angle at } 90^{\circ} & 0.77[0.59 ; 0.88] \\
\text { Alpha angle at } 45^{\circ} & 0.77[0.59 ; 0.88] \\
\text { Femoral head-neck offset } & 0.70[0.47 ; 0.84] \\
\text { Pincer impingement } & \\
\text { Acetabular version angle } & 0.90[0.81 ; 0.95] \\
\text { Lateral centre-edge angle } & 0.78[0.61 ; 0.89] \\
\text { Acetabular index } & 0.93[0.84 ; 0.97]\end{array}$

Data are intraclass correlation coefficients and $95 \%$ confidence intervals are given in brackets

prevalence of cam morphotype using these previously described imaging criteria and the width of the reference intervals found in our study suggest that the currently used morphometric criteria for cam-type FAI need to be redefined. More specifically, our results suggest that the alpha angle is not an appropriate parameter to define cam-type morphotype.

For pincer-type FAI, all the $95 \%$ reference interval limits for the evaluation of the acetabular morphology were also beyond the abnormal thresholds reported in the literature, however, to a lesser extent than for cam-type FAI [5, 13, 15-20] (Table 3). Of note, the reference intervals for the lateral centre-edge angle for men $\left(22,47^{\circ}\right)$ and women $\left(21,44^{\circ}\right)$ were very close to what is found in the literature. A lateral centre-edge angle equal to or greater than $45^{\circ}$ is suggestive of acetabular overcoverage and a lateral centre-edge angle equal to or less than $20-25-30^{\circ}$, depending on the authors, is classically thought to suggest hip dysplasia [16, 32]. Among the parameters that we evaluated, the lateral centre-edge angle has been most widely used in the literature to evaluate acetabular morphology and our results confirm previously reported cut-off values [33].

In our study, the upper limits of the reference intervals for the alpha angle and the femoroacetabular offset were similar between men and women, coherent with Pollard et al. [21], but divergent with Hack et al. [17]. For the pincer morphotype, there is also a controversy about the difference between men and women as far as these morphological variants are concerned $[22,23]$. We found that differences between genders were less than $3^{\circ}$ for the means of all morphometric parameters of pincer-type FAI. These small differences might be clinically irrelevant.

Our limits of confidence intervals were similar between right and left hips, comparable with previous reports [23]. Laborie et al. analysed the prevalence of the cam-type and pincer-type impingement signs and no significant differences were noted between the left and right sides [23].

This study has some limitations. First, our normal values were derived from a limited sample of 94 patients corresponding to 188 hips. However, according to Altman, a reference interval can be reliably calculated if the sample size of a study is more than 50 observations [30].

Second, defining a normal sample population is a difficult task and may be subject to many biases. Although our sample was not selected from healthy volunteers, we prospectively included consecutive patients presenting for non-orthopaedic pathology to our department and excluded all patient with any history of current or past hip pathology or symptoms. Furthermore, we took great care to prospectively exclude any patients with signs of hip pathology (including OA) at CT, based on strict criteria. No physical evaluation of the hips was performed. However, we believe that the prospective exclusion of all patients with any symptoms, clinical history or CT signs of hip pathology allowed us to limit this potential bias because pain is a key symptom in FAI. Without pain as the main complaint, the diagnosis of FAI generally cannot be made. Furthermore, by excluding all patients with OA signs at CT, we ensured that potential abnormalities such as osteophytes would not bias our anatomic measures.

Third, part of our analysis was based on 100-mm-thick coronal MPR, simulating pelvic radiographs. Even though we did not obtain radiographs in these patients, this previously described technique allowed us to obtain reformatted images that precisely meet the requirements that are necessary for the radiographic evaluation of FAI morphotypes [5, 18].

Fourth, the interobserver agreement, which was substantial to almost perfect, was evaluated only on a small subset of randomly selected patients. However, the purpose of this analysis was mainly to verify the consistency of the application of the measurement method by observer 1, not the overall evaluation of the interobserver agreement for the assessment of FAI signs at CT.

Fifth, the imaging was performed on three different devices, which could have had an effect on the measurements. However, this potential bias was limited by the fact that all three devices were from the same manufacturer, and image quality was optimized by the same team of radiologists on all three of them, to ensure homogeneous quality.

In conclusion, we determined gender- and side-specific means and $95 \%$ reference intervals of the cam and pincer morphometric parameters in the asymptomatic patient population based on high-resolution multidetector CT. The $95 \%$ reference interval limits calculated for the FAI signs were all far beyond the abnormal thresholds found in the literature for cam-type and to a lesser extent for pincer-type FAI, except for the lateral centre-edge angle for which reference intervals are similar to previously reported normal values. Our results suggest that current definitions of FAI morphotype at imaging should be used with care. More specifically, this current work strengthens previous studies suggesting that the alpha angle is not an appropriate parameter to define cam-type FAI and needs to be redefined [19]. This parameter just seems to reflect normal anatomical variation. Having $95 \%$ of an 
asymptomatic population presenting alpha angles between $30^{\circ}$ and $83^{\circ}$ (depending on the quadrant where it is measured) is an indication that what has been considered as a pathological feature in the literature (an alpha angle $>50^{\circ}, 55^{\circ}$ or $60^{\circ}$ ) just represents a normal variant. Under certain circumstances, such as in specific sports activities, the presence of a certain morphotype might predispose to the development of FAI. The pathogenesis of FAI is beyond the scope of this study, but in view of our results, it should be kept in mind that FAI remains a clinical diagnosis and that preventive surgery in asymptomatic subjects should not be planned on the basis of the presence of imaging signs alone [28, 34].

Acknowledgements The scientific guarantor of this publication is Dr. Patrick Omoumi. The authors of this manuscript declare no relationships with any companies whose products or services may be related to the subject matter of the article. The authors state that this work has not received any funding. One of the authors has significant statistical expertise. Institutional review board approval was obtained. We received approval from the institutional ethical committee of our institution: Commission d'Éthique Biomédicale Hospitalo-Facultaire, Cliniques Universitaires Saint Luc - Université Catholique de Louvain. Written informed consent was obtained from all subjects (patients) in this study. Methodology: prospective, observational, performed at one institution.

\section{References}

1. Ganz R, Parvizi J, Beck M, Leunig M, Nötzli H, Siebenrock KA (2003) Femoroacetabular impingement: a cause for osteoarthritis of the hip. Clin Orthop Relat Res 417:112-120

2. Ito K, Leunig M, Ganz R (2004) Histopathologic features of the acetabular labrum in femoroacetabular impingement. Clin Orthop Relat Res 429:262-271

3. Wagner S, Hofstetter W, Chiquet M, Mainil-Varlet P, Stauffer E, Ganz R, Siebenrock KA (2003) Early osteoarthritic changes of human femoral head cartilage subsequent to femoro-acetabular impingement. Osteoarthr Cartil 11:508-518

4. Byrd JWT (2014) Femoroacetabular impingement in athletes: current concepts. Am J Sports Med 42:737-751

5. Tannast M, Siebenrock KA, Anderson SE (2007) Femoroacetabular impingement: radiographic diagnosis-what the radiologist should know. AJR Am J Roentgenol 188:1540-1552

6. Kassarjian A, Brisson M, Palmer WE (2007) Femoroacetabular impingement. Eur J Radiol 63:29-35

7. Matsuda DK, Carlisle JC, Arthurs SC, Wierks CH, Philippon MJ (2011) Comparative systematic review of the open dislocation, miniopen, and arthroscopic surgeries for femoroacetabular impingement. Arthroscopy 27:252-269

8. Ng VY, Arora N, Best TM, Pan X, Ellis TJ (2010) Efficacy of surgery for femoroacetabular impingement: a systematic review. Am J Sports Med 38:2337-2345

9. Parvizi J, Leunig M, Ganz R (2007) Femoroacetabular impingement. J Am Acad Orthop Surg 15:561-570

10. Beaulé PE, Zaragoza E, Motamedi K, Copelan N, Dorey FJ (2005) Three-dimensional computed tomography of the hip in the assessment of femoroacetabular impingement. J Orthop Res 23:12861292

11. Clohisy JC, Carlisle JC, Beaulé PE et al (2008) A systematic approach to the plain radiographic evaluation of the young adult hip. $\mathrm{J}$ Bone Joint Surg Am 90(Suppl 4):47-66
12. James SLJ, Ali K, Malara F, Young D, O'Donnell J, Connell DA (2006) MRI findings of femoroacetabular impingement. AJR Am J Roentgenol 187:1412-1419

13. Nötzli HP, Wyss TF, Stoecklin CH, Schmid MR, Treiber K, Hodler J (2002) The contour of the femoral head-neck junction as a predictor for the risk of anterior impingement. J Bone Joint Surg (Br) 84:556-560

14. Pfirrmann CWA, Mengiardi B, Dora C, Kalberer F, Zanetti M, Hodler J (2006) Cam and pincer femoroacetabular impingement: characteristic MR arthrographic findings in 50 patients. Radiology 240:778-785

15. Ecker TM, Tannast M, Puls M, Siebenrock KA, Murphy SB (2007) Pathomorphologic alterations predict presence or absence of hip osteoarthrosis. Clin Orthop Relat Res 465:46-52

16. Gosvig KK, Jacobsen S, Sonne-Holm S, Palm H, Troelsen A (2010) Prevalence of malformations of the hip joint and their relationship to sex, groin pain, and risk of osteoarthritis: a population-based survey. J Bone Joint Surg Am 92:1162-1169

17. Hack K, Di Primio G, Rakhra K, Beaulé PE (2010) Prevalence of cam-type femoroacetabular impingement morphology in asymptomatic volunteers. J Bone Joint Surg Am 92:2436-2444

18. Kang ACL, Gooding AJ, Coates MH, Goh TD, Armour P, Rietveld J (2010) Computed tomography assessment of hip joints in asymptomatic individuals in relation to femoroacetabular impingement. Am J Sports Med 38:1160-1165

19. Sutter R, Dietrich TJ, Zingg PO, Pfirrmann CWA (2012) How useful is the alpha angle for discriminating between symptomatic patients with cam-type femoroacetabular impingement and asymptomatic volunteers? Radiology 264:514-521

20. Tönnis D, Heinecke A (1999) Acetabular and femoral anteversion: relationship with osteoarthritis of the hip. J Bone Joint Surg Am 81: $1747-1770$

21. Pollard TCB, Villar RN, Norton MR et al (2010) Femoroacetabular impingement and classification of the cam deformity: the reference interval in normal hips. Acta Orthop 81:134-141

22. Chakraverty JK, Sullivan C, Gan C, Narayanaswamy S, Kamath S (2013) Cam and pincer femoroacetabular impingement: CT findings of features resembling femoroacetabular impingement in a young population without symptoms. Am J Roentgenol 200:389-395

23. Laborie LB, Lehmann TG, Engesæter I, Eastwood DM, Engesæter LB, Rosendahl K (2011) Prevalence of radiographic findings thought to be associated with femoroacetabular impingement in a populationbased cohort of 2081 healthy young adults. Radiology 260:494-502

24. Reichenbach S, Jüni P, Werlen S et al (2010) Prevalence of cam-type deformity on hip magnetic resonance imaging in young males: a cross-sectional study. Arthr Care Res (Hoboken) 62:1319-1327

25. Kapron AL, Anderson AE, Aoki SK, Phillips LG, Petron DJ, Toth R, Peters CL (2011) Radiographic prevalence of femoroacetabular impingement in collegiate football players: AAOS exhibit selection. J Bone Joint Surg Am 93:e111(1-e1110)

26. Omoumi P, Thiery C, Michoux N, Malghem J, Lecouvet FE, Vande Berg BC (2014) Anatomic features associated with femoroacetabular impingement are equally common in hips of old and young asymptomatic individuals without CT signs of osteoarthritis. AJR Am J Roentgenol. doi:10.2214/AJR.12.10083

27. Horowitz GL, Altaie S, Boyd JC et al (2008) Defining, establishing, and verifying reference intervals in the clinical laboratory; approved guideline-third edition CLSI document C28-A3. Clinical and Laboratory Standards Institute, Wayne

28. Collins JA, Ward JP, Youm T (2013) Is prophylactic surgery for femoroacetabular impingement indicated? A systematic review. Am J Sports Med. doi:10.1177/0363546513499227

29. de Bruin F, Reijnierse M, Farhang-Razi V, Bloem JL (2013) Radiographic signs associated with femoroacetabular impingement occur with high prevalence at all ages in a hospital population. Eur Radiol 23:3131-3139

30. Altman DG (1990) Practical statistics for medical research. Chapman \& Hall/CRC, Boca Raton 
31. Rakhra KS, Sheikh AM, Allen D, Beaulé PE (2009) Comparison of MRI alpha angle measurement planes in femoroacetabular impingement. Clin Orthop Relat Res 467:660-665

32. Harris-Hayes M, Royer NK (2011) Relationship of acetabular dysplasia and femoroacetabular impingement to hip osteoarthritis: a focused review. PM R 3:1055-1067.e1
33. Werner CM, Ramseier LE, Ruckstuhl T et al (2012) Normal values of Wiberg's lateral center-edge angle and Lequesne's acetabular index-a coxometric update. Skelet Radiol 41:1273-1278

34. Palmer WE (2010) Femoroacetabular impingement: caution is warranted in making imaging-based assumptions and diagnoses. Radiology 257:4-7 